\title{
CULTURAL CHANGE AND PERPETUATION IN ORGANISATIONS: EVIDENCE FROM AN ENGLISH EMERGENCY AMBULANCE SERVICE
}

\section{INTRODUCTION}

The effectiveness of a wide variety of organisations has been linked to the culture of the organisation, including those in health care (Konteh et al. 2010). There is some intuitive appeal in the proposition that organisational culture may be a relevant factor in healthcare performance, but the possible relationship between culture and performance is not conclusively established, since both 'culture' and 'performance' as variables are conceptually and practically distinct (Kotter and Heskett 2011; Schein 2011). For instance, Scott et al. (2003) argued that articulating the nature of that relationship is difficult and simple assumptions, such as 'strong cultures lead to good performance', are not supported by their review. They concluded that the evidence suggests a more contingent relationship, in that particular aspects of performance valued within different cultures may be enhanced within organisations that exhibit such cultural traits; but only those aspects.

Nevertheless, changing organisational culture is now a familiar prescription for health sector reform in the UK. For example, the Mid Staffordshire NHS Foundation Trust Public Inquiry (Francis Report 2013) into the patient deaths and other recent reports (Care Quality Commission CQC 2015; Kirkup 2015) emphasise the need for organisations to create the right culture to deliver high-quality care that is responsive to patients' needs and preferences. Similarly, Konteh et al. (2010), reflecting on the Bristol Royal Infirmary Inquiry, identified an 'increasing interest' in managing organizational cultures as a lever for improving quality of care (ibid 111). However, this assumes that the National Health Service (NHS) and its constituent organisations possess a discernible culture with some bearing on performance and quality (Department of Health DH 2001; Mannion et al. 2005; Wankhade 2012).

Moreover, the issue of how organisational cultures and sub-cultures may impede, rather than promote, organisational change is also important (Harris and Ogbonna 1998; Morgan and Ogbonna 2008). Ogbonna and Harris (2014) argue that there has been limited research into the perpetuation of organisational cultural traits, especially in the context of managerial efforts to promote change. They then examine the endurance of pre-existing organisational cultures, making them resistant to imposed change, and suggest internal and external factors that may obstruct the attempted management of culture. Their framework informs our analysis of the management and perpetuation of organisational culture in one large NHS ambulance trust and how this affects the prospects for organisational change. This article explores the nature of culture change and perpetuation, therefore, within an ambulance service and how this affects the prospects for organisational change. The original study on which it is based responds to the call for more research into healthcare systems, especially from management and policy perspectives (McCann et al. 2013; Wankhade and Mackway-Jones 2015). 


\section{ORGANISATIONAL CULTURES AND SUB-CULTURES}

The concept of organisational culture has become more prominent in studies of organisational change recently, since structural changes have come to be seen as inadequate on their own as a means for reform (Jorritsma and Wilderom 2012; Konteh et al. 2010)). However, there are varied perspectives on organisational cultures. One view regards organisations as essentially unitary entities, with single over-riding cultures. Such cultures would be devised by senior managers and imposed top-down. The shared values and assumptions contained within them are then absorbed by employees through socialisation. The culture should be in line with the mission, higher objectives and strategies of the organisation and it can be adjusted to be so. Thus culture may be seen as relatively straightforward to control, manage and change and organisations regarded as being changed easily by manipulating cultures. Therefore, managing through culture would be an efficient and effective form of management control (Mannion et al. 2005; Wilderom et al. 2000). This perspective reflects an instrumental rational view of organisations. Instrumental rationality entails an assessment of identifying the 'best' (e.g. the most cost-effective) means of achieving a given (maybe imposed) end (Broadbent and Laughlin 2009).

However, this interest in organisational culture is problematic, for instance because there are many definitions of culture and views of how it impacts upon organisational behaviours (Smircich 1983; Hatch 1993). As Browaeys and Price (2008, 9) note, 'one can never use the term culture without being obliged to give a range of definitions that contradict each other'. Nevertheless most definitions do recognize the socially constructed nature of a phenomenon that is expressed in terms of patterns of behaviour. Moreover, culture operates in layers and Schein (1985) identifies a pluralistic dimension to culture, operating at three distinct levels. The first comprises 'artefacts', including rewards, rituals and ceremonies. These are concerned with the observational patterns of behaviour (for example, green uniform for ambulance crews). At the next level are the espoused 'beliefs and values' which may be used to justify particular behavioural patterns (for example, the valuing of speedy ambulance response). At the third level are the 'assumptions', which are the real and largely unconscious beliefs and expectations held and shared by individuals (such as, uniformed emergency service versus emergency health service). Successfully changing cultures, therefore, requires that change impacts on all these levels, which may prove difficult. The pluralist view of culture finds support in the literature (see Smircich 1983; Martin 1992) notwithstanding alternate perspectives on studying culture, such as those based on leadership, religion or gender.

Again, organisations may be seen as fragmentary rather than unitary and thus the location for competition and conflict between their parts as well as consensus. The subunits may have distinctive belief systems (sub-cultures), which strongly influence the values, attitudes and actions of their members, possibly in ways which are at odds with the dominant culture. Moreover, this may be an even greater issue within the public services because the nature of the public sector centres on the delivery of professionally based services, notably in local government and health services. Traditionally, there have been major and often dominant professions such as doctors, the police and social workers. This has led, within the NHS in particular, to the development of new professional groups 
who have sought professional recognition to defend their roles within services areas dominated by these, more well established, groups (Wankhade et al. 2015). Consequently, the continuing expansion of new specialisms, each of those seeking formal recognition of their professional status, has further increased the challenge presented by competing subcultures within the public sector as a whole. A communicative rationality perspective on organisations may be more appropriate here. Communicative rationality is based on systematic discourse between stakeholders, leading to consensus about ends and means, which are not predefined, but arrived at through discourse within defined rules of engagement (Broadbent and Laughlin 2009).

The necessity of understanding the place of organisational sub-cultures in driving cultural change follows from this analysis. Examples from public sector organisations can be used to illustrate the point. For instance, Williams van Rooij (2011) concluded that successful innovation in higher education requires the consensus of two sub-cultures, namely the technologist sub-culture and the academic sub-culture. Again, Fitzgerald and Teal (2004) found that cultural differences between groups of doctors, nurses and others are not limited to being between the occupational groups but include differentiation within the medical profession, based upon specialization, generation, educational background, employment status and engagement with the organisation.

Similarly, the significance of sub-cultures in the ambulance service is highlighted by Wankhade (2012), who used Schein's (1996) typography in an ethnographic study of an ambulance trust to identify three distinct occupational sub-cultures.

1. The 'Operator' culture of the front-line crews (paramedics and technicians) who respond to all emergency 999 calls.

2. The 'Engineering' culture of the Call takers and Call dispatchers who receive all 999 calls and dispatch vehicles to the scene of an emergency;

3. The 'Executive' culture of the Chief Executive and the senior executive team.

A variety of assumptions and values were found in the different occupational groups: there is no 'single' ambulance culture, but rather 'multiple' cultures. Respondents spoke as members of their occupational 'tribes', each with its own assumptions, values and beliefs, reinforced by their specific attitudes towards performance (Wankhade 2012).

\section{ORGANISATIONAL CULTURE, CHANGE AND PERPETUATION}

Scholars have also recognised different perspectives on cultural change, including Martin's (1985) view of 'cultural purists' and 'cultural pragmatists'. Similarly Ogbonna and Harris (2002) identify 'optimists', 'pessimists' and 'realists'; as (i) those who believe culture is significantly susceptible to conscious management action; (ii) those who reject that view completely; and (iii) those who argue that only some aspects of culture may be changed and only under certain organisational conditions. 
Ogbonna and Harris (2014) call for an understanding of the dynamics of organisational culture that encompasses the idea of cultural perpetuation. Perpetuation is defined by them as the 'continuation of core cultural values, beliefs, and assumptions such that they become enduring in such a way that new generations of organisational members are conditioned to adopt them in responding to various organisational contingencies' (ibid 668). In their study of an English Premier League Football club, they found evidence of five intra-organisational and extra-organisational factors that have implications for both culture management and cultural perpetuation. These are:

1. Historical Legacy: which includes tales of founding fathers, great victories, etc. (in this case, the history of paramedics as uniformed emergency service employees rather than as health care practitioners);

2. Organisational Symbolism: the role of myths, heroes and associated artefacts (e.g. uniforms and response time targets);

3. Subcultural Dynamics: the existence and interaction of sub-cultures (e.g. those of different ambulance service 'tribes' such as executives, middle managers, paramedics and control room staff);

4. Employment Practices: HRM interventions that can contribute to cultural change or perpetuation (such as education and training initiatives in the ambulance service); and

5. Extra-organisational Influences: the effects of constituent parts of organisational contexts on culture management, change and perpetuation in organisations (for example, of central government on ambulance services).

In discussing the importance of these factors, Ogbonna and Harris emphasise the role of internal actors, not as passive recipients of institutional pressures, but as active participants whose interactions with their immediate environments contribute to the creation and preservation of values.

Previous studies of unsuccessful attempts at cultural change concentrate on employee resistance and/or managerial ineffectiveness and design deficiencies (Schneider et al. 2011; Wankhade and Brinkman 2014). The framework provided by Ogbonna and Harris (2014) suggests that failure to change culture may result more from peculiarities in the culture itself than in the way the change programme was implemented. In particular, organisations (such as ambulance services) with a strong history of previous success and a contingent combination of internal and external factors that promote and perpetuate existing values seem likely to develop cultures which are less susceptible to management control. Similarly, Anand et al. (2005) argue that socialisation processes influence individuals into accepting on-going practices within the organisation and their rationalisations, even when these are unethical as at, for example, Enron, WorldCom and Parmalat. (The issue of opportunistic behaviour is also relevant to the English ambulance service: see, for example, Heath and Radcliffe 2007). 


\section{METHODOLOGY}

Data was collected by the first author during 2007-09 at a trust, which we call 'Delta trust' to ensure confidentiality. Factors perpetuating existing cultural values and preventing cultural change are analysed in the research. Due to the exploratory nature of the study, the primary aim was to access the different experiences of a range of staff within the organisation in understanding their social settings (Watson 2011). Rich case studies have a considerable potential to play a larger and more mainstream role in organisation and management studies (Yin 2009).

More than seventy qualitative, semi-structured interviews were conducted in two phases to collect the data. Interviews lasted between 30 to 90 minutes and were digitally recorded to be transcribed later. A 'stratified purposeful' strategy (Miles and Huberman 1994, 28) was considered to be the most effective method to recruit the participants in this study to facilitate understanding of the social dynamics underlying the case. The participants included senior board executives, managers, and frontline staff- paramedics, the 999 call handlers and the dispatchers working in the control room (table 1). This helped to identify and analyse the interdependence between different occupational groupings (Wankhade 2012) allowing a better understanding of the dynamics of the culture in the organisation.

\section{Table 1 Here}

Although there were only relatively few interviews with paramedics, this was compensated for by the time spent on observation of paramedics on the road and at the ambulance station, which has supported the findings. Indeed, about 100 hours of nonparticipant observation informed this study (table 2). Observation was carried out at the corporate level; at the level of middle executives and managers; and frontline staff paramedics and control room; allowing for an analysis of the interdependence between these various organisational dimensions. The researcher attended open trust board meetings, internal executive meetings and middle management team meetings. Operations in the control rooms were observed and time was also spent in the ambulance stations, travelling with ambulance crews and in the canteen where managers, junior executives, and frontline staff took breaks. Observation was complemented with informal conversations in the 'corridors' with staff.

\section{Table 2 Here}

Such an approach is in conformity with the use of multiple data collection strategies to build the in-depth case and improve the quality of the case study research (Eisenhardt and Graebner 2007). The observation data were recorded manually in books by writing down within 2-3 days of the observation. Interview data were transcribed manually and the 
responses to the key themes were analysed repeatedly and through content analysis until theoretical saturation was reached (Lincoln and Guba 1985; Charmaz 2003). Through this method the process of culture change was explored and factors responsible for perpetuating cultural values and beliefs identified. Ethical approval for the larger study was obtained from the local NHS research ethics committee.

\section{RESULTS}

The research revealed factors that contributed to the continuation of the cultural norms, values and beliefs that hampered management change efforts. Each of these factors is discussed below.

\section{Historical Legacy}

When the Health Service was created in 1948, the Ambulance Service became part of local government not the NHS. It followed the established emergency services in adopting artefacts like uniforms and rank structures (Pollock 2013). Since becoming part of the wider NHS in 1974, the Ambulance Service has been evolving from a simple transport service into a pre-hospital health care service and is the first point of access for a wide variety of health problems. However:

The ambulance service is perceived as the transport arm of the NHS, simply there to get patients from their homes or the scene of an accident to the nearest accident and emergency department. (Senior board executive)

Historically, ambulance services have been perceived primarily as an emergency service with training and service provision organised around the need to address major trauma such as road traffic collision, severe breathing problems or cardiac arrest. Since becoming part of the NHS, the service has made progress in its transformation from a patient transport organisation to a clinically trained workforce (National Audit Office NAO 2010). It is estimated, however, that less than ten per cent of emergency 999 callers have a life threatening condition (Evans et al. 2014) and alternate care options are provided to most ambulance service users (Heath and Radcliffe 2010; Wankhade 2011).

This has given rise to calls for organisational change, particularly in the role, education and training of paramedics so that they may carry out a wider range of activities, such as referrals, giving advice and treatment at the scene. Calls for professionalization of the work force (First et al. 2012) have resulted in paramedic training moving into the universities (College of Paramedics 2015) with a range of advanced specialist paramedic roles being developed. Staffs with specialist roles (such as critical care paramedics or emergency care practitioners) are now equipped with enhanced knowledge and skills needed to make complex decisions about patient care. However, tension seems to have arisen around these developments. For example: 
Currently we still have a large number of staff who are highly competent in psycho motor skills that they've been taught. ...I need to change it into a culture where they can think, where they can assess, where they can decide not just against algorithms but actually against the scope of practice and so that's a significant migration in individuals and in systems. (Senior clinician)

I think that there's a need to change the nature of the workforce...we need to take a non-professional blue-collar workforce and migrate it into being a professional workforce. (Clinician)

These quotations suggest there are some continuing challenges around reluctance to accept the changing role of ambulance staff wholeheartedly.

Thus historical factors help promote the perpetuation of cultural beliefs and preferences as highlighted by Obgonna and Harris (2014). During informal conversations with staff, the dilemma of progressing from a historical trauma-based organisation to a modern clinically trained pre-hospital mobile healthcare service was often mentioned as a factor which thwarted modernisation efforts. Vestiges of the old command and control culture, accompanied by a blame culture, hierarchical and top-down management styles, resistance to change and risk-averse behaviour are some of the historical factors within the ambulance service, which were reported by Wankhade and Brinkman (2014). Indeed risk aversion in the ambulance services is such that conveyance of patients to emergency departments may be still the default safety net because 'you don't lose your job from taking a patient to hospital' (O'Hara et al. 49).

\section{Organisational Symbolism}

While senior executives extolled the virtues of developing new values and beliefs around professionalization of the service, symbolic expressions which still supported the existing culture were also expressed.

A lot of our staff don't think going to patients with minor things and leaving them at home is a worthwhile thing to have done. What our staff, in the way that they were recruited, if you like, the adrenalin junkies, they get there, they save someone's life, they drive somewhere else, deliver the patient to a team that's all... it's like the telly isn't it?. They didn't join up, as they will tell you, to be district nurses. (Senior Board Executive)

You know there is an obsession with the 8 minutes and a realisation - if you took it away I guess many things, in some areas, could get worse. (Policy expert) 
The purpose of such changes was the development of a 'new culture' focussing on developments set out by national ambulance policy review, Taking Healthcare to the Patient (DH 2005). Recommendations from the review required a quantum culture shift for the ambulance service from a heroic but straightforward transport organisation to a clinically driven emergency service. This involved developing new management structures, treating a greater number of patients in the community and performing an enhanced clinical role (Wankhade and Brinkman 2014).

The national ambulance review (DH, 2005) built upon the previous efforts to modernise and professionalise ambulance service education (through paramedic degrees), regulation (Health Professional Council) and streamlined performance management; thus presenting a 'pivotal moment' to the ambulance trusts in becoming a clinically professional service within the NHS. However, cultural artefacts, such as blue flashing lights and response targets, persist as organisational symbols, reflecting the historical legacy, and nonachievement of targets is still considered taboo by senior executives (McCann et al. 2015; NHS Confederation 2011).

I think over the years it does seem to be very target driven and it doesn't matter you know what the treatment's like as long as you get there in time and I think that is the culture that a lot of people expect to feel. That's what most people believe even though they don't agree with it. (Manager)

You get fed up in chasing figures, numbers...There is no consideration of individuals. You then become creative in interpreting and massaging targets and figures. (Senior Board Executive)

The symbolic dimensions of these sub-cultures may also have played a part in the mutual mistrust identified at Delta.

If I go and see a manager and communicate my indifference or otherwise then I can see one but I just don't want to because I know it won't make any difference and that's what the staff I think are reflecting on. (Paramedic)

Actually there's a culture in certain parts of the organisation and probably this part, in the middle management, where managers believe that they know all the answers ... they'll have to have the last say in everything. (Board executive)

\section{Sub-cultural Dynamics}

Obgonna and Harris (2014) assert that the importance of subcultural dynamics in cultural perpetuation is linked to subcultural centrality and subcultural domination. Wankhade (2012) documented the relative influence of the three main sub-groups (executives, paramedics and control room staff) and highlighted the salience of senior executives 
attempting to drive the culture change agenda. Here evidence is presented about the difference in perception of each of the different sub-cultural groups especially around the key performance target of eight-minute response time:

It's now very difficult when you are talking to staff about performance improvement, that they just see it all as a code for hitting the target as opposed to genuinely trying to make change improvements for the patients themselves. (Board executive)

My colleagues don't view performance because one of the major features in the ambulance service is one job at a time... No they don't really give a monkeys and do you know why they don't? It's because the minute they come here for a 12-hour shift, whether it be a day shift or a night shift or a link shift it's a job, after job, after job. (Paramedic)

I don't necessarily believe that the national targets are necessarily the most accurate or realistic targets and ...therefore, I think there is an issue of morale as well that if you're performance targets are too high and unrealistic then they're very hard to achieve and people get very demoralised. (Manager)

The above comments reflect the variance in the attitudes of the different subcultural groups at Delta towards the issue of performance targets. Radcliffe and Heath (2009) argued that the earlier performance measurement regime and the prevailing organisational culture in the ambulance service reinforced each other to promote the primacy of response times; thus acting as something of a 'brake' on the reform process. Although a broader based regime is now in place (Heath and Wankhade 2014), there has yet to be any firm research evidence as to whether that has affected the prevailing culture.

\section{Employment Practices}

Some aspects of employment practices appeared significant in promoting cultural endurance and undermining the cultural change efforts. We have already referred to the somewhat contested change in the roles of paramedics and control room staff.

I think the underpinning thing for me... is actually delivering the new agendas around education. If I think that a competent clinician is my short-term aim in order to deliver high quality care, I need a significant investment, both in future clinicians and present clinicians to take them and their competencies to where they need to be. (Clinician)

Additionally, the insular internal recruitment process and the limited role of Delta's managers in operational and strategic aspects stood out. Several factors appear to have contributed to this. Traditionally, most senior personnel joined the service as front-line paramedics and worked their way through to managerial/executive positions. Many 
managers stated that it was not uncommon to find that senior executives (including chief executives) on the Trust boards had come from the 'ranks':

Traditionally ambulance services had promoted and recruited from within their own ranks and that this was a typical uniform service approach in which if one worked for it long enough, one would get promoted because it's his/her turn. This has resulted in a lack of ownership, understanding and accountability at all levels in the organisation and where the senior executive team were viewed as 'Generals' and lots of time is spent in looking 'upwards' for directions. (Station Manager)

Furthermore, the eight-minute response time target is too short to allow any managerial intervention in 'real time' and, therefore, influence resides with the control room staff. Real time performance data is available to executives and managers but the allocation of resources is a preserve of the control room staff. This allows little scope for managers to deal with performance issues as they arise.

Lack of opportunities for training and clinical education, often side-lined due to operational exigencies, was another issue highlighted by some of the managers during the interviews as affecting both themselves and the staff:

I'm not sure you can change the nature of the workforce by giving them 5 days a year to train. (Clinician)

This has a significant bearing on executive efforts to bring cultural change. The management focus on performance targets further affected the personal development of this group. One senior executive expressed his 'frustration about the lack of managerial skills in communicating the message' to the front-line staff. Some middle managers, on the other hand, complained about a 'lack of genuineness' on the part of senior management in involving them in actual decision-making processes and developing organisational strategies.

Operational managers were isolated from front-line staff due to shift patterns and from each other due to the distances involved, which resulted in their engagement in the organisation being limited to an implementation role. (This is a general issue in organisations: see Currie and Procter 2005). Thus they seemed to have limited influence on either the contents of the strategy or the operational activities supposed to deliver it. Perhaps unsurprisingly, these middle managers could seem 'reluctant managers' (Scase and Goffee 1989). However, there were positive developments witnessed at Delta. For example, the development of the managerial strategic function was recognised by senior management and training programmes were enhanced.

\section{Extra-organisational Dimension of Organisational Cultural Perpetuation}


Obgonna and Harris (2014) demonstrate the importance of an extra-organisational dimension in understanding cultural perpetuation by particularly highlighting the role of football fans in their study. In our study, we see the influence of other NHS organisations and the central government as having a significant effect.

I think managers are under more pressure and I think managers do have a perceived tension. They understand what it is that's happening in the clinical domain and have great tension within themselves about saying you should not do this, you should do this in order to deliver targets versus you should do this, you shouldn't do this for individual patients. (Clinician)

I think, however we are an organisation which is under political control whatever people say and the bottom line is that unless we deliver our headline targets we will be deemed to be a failed organisation and however much we squeal that we are doing it for the patients we will be removed. (Clinician)

However, and significantly, the interviews suggested that other stakeholders, such as service users and other emergency services (police and fire), were regarded as having less influence on the organisational culture. This can be related to the expanding, but still limited, role and influence of the ambulance services within the wider NHS. Many respondents referred to the relative inability of individual ambulance trusts to influence events which might have important implications for meeting their performance targets within that network:

Ten years ago we were very much part of the emergency services. Over the last 10 years we have become more and more meshed into the NHS way of working and we are in kind of no man's land at the moment because the emergency services (fire and police) no longer see us as a full partner with them. (Senior executive)

During the non-participant observations and ambulance ride-ons, this aspect was amplified. Discussions in the canteen pointed out the dilemma of being perceived as an emergency service akin to police and fire (wearing uniforms and attending emergencies) as against the expectation of been seen as an emergency pre-hospital care provider within the NHS family. Central government is clearly a significant external influence on ambulance services. However, frustration was expressed at Delta concerning the many and sometimes contradictory Government initiatives.

Because they are all complete opposite in terms of incentives and the direction of travel that you would take to achieve any one of those... Sometimes you can sit back and you end up laughing because otherwise you would just cry. (Board executive)

The facts are not joined up. Because if you think about it and think about well hang on, well how does Payment by Results, Foundation Trusts, Practise-Based 
Commissioning, Taking Health Care to the Patient - how does that all actually

tie in. (Board executive)

Considerable pressure from successive governments to promote the wider role of the ambulance professional, however, has inevitably had some effect in addressing the countervailing factors identified above (Radcliffe and Heath 2009). Furthermore, there are increasing numbers of instances suggesting that senior managers from other NHS services are coming into the organisation and likewise there is a growing movement of paramedics and nurses moving into different sectors of the NHS. Increasingly, medical personnel are being employed by individual ambulance trusts including as medical director. But some reservations remain. For example:

I have a horrible feeling that ...in 5 or 10 years' time they \{the ambulance trust\} will be carrying on doing more of the same... I'm not confident that I could say in 10 years' time we will have a fantastic ambulance service that's really adding value to the patient. (Policy expert)

\section{DISCUSSION}

A key contribution of this study is that it presents a rich description and analysis of a service, which is rather neglected in management and policy studies. Moreover, the concept of cultural change and perpetuation has been highlighted in the literature as needing further study (Ogbonna and Harris 2015). We argue that the ambulance service, with its historical legacy and combination of intra- and extra-organisational cultural factors that perpetuate existing values, is likely to develop enduring cultures that are resistant to executive control. These findings support the work of Ogbonna and Harris (2014).

Previous studies of unsuccessful culture change in the ambulance services focussed on sub-cultural groups' behaviour and employee resistance (Wankhade 2012) and unintended consequences of culture change management (Wankhade and Brinkman 2014). Here we suggest that the perceived failure on the part of senior executives to manage or change culture is probably due to the nature of the culture as well as the approach undertaken to implement changes. In so far as this is true, elements of the culture may well impede Government policy initiatives; such as promoting a wider role for paramedics, integrating ambulance services into the wider NHS and enhancing clinical and leadership practices.

Blaber and Harris (2014) regard the development of clinical leadership for paramedics as essential for ambulance professionalization. Thus workforce development has become a key policy initiative that is seen to be an integral element of the ambulance modernisation programme (Association of Ambulance Chief Executives AACE 2011; NAO 2011; NHS England 2013). However, considerable variation in the nature of the associated educational programmes has been cited as a potential barrier to establishing a truly professional workforce (Lovegrove and Davis 2013). Moreover, McCann et al. (2013) hold that changes advocated at the top are not necessarily accepted at ground level 
and that the professionalization strategy promoted at senior level has so far had limited traction due to power issues and other institutional priorities/pressures. They concluded that 'institutional work in such a setting is necessarily less about trying to change organizations and institutions, and more about maintenance' (ibid 772).

Based on the Delta case, we argue that the effect of an organisational culture deeply embedded within the history of the service supported these tendencies. Moreover, the earlier performance measures reinforced the cultural norms around response times and emphasised the rapid transportation of patients (Wankhade et al. 2015) . The recognition of the need to change these measures and a questioning of the role of targets within the health service suggests that government is increasingly aware of these issues. Thus the recent changes to the performance measurement regime seem supportive of the broader paramedic role (Heath and Wankhade 2014), although simply expanding the performance measures, whilst welcome, is unlikely to be enough on its own.

The prevalence of the factors identified by Ogbonna and Harris (2014) suggest that changing organisational cultures in such settings is much less easy to do than the policy documents seem to imply. The point made by Anand et al. (2005) about the strength of socialization also seems to be supported. However, in Ogbonna and Harris' case, the five factors they identified uniformly support cultural perpetuation; whereas in our study, two factors, employment practices and extra-organisational influences, seem more ambiguous in that education and training can support change and government policy definitely does. Also, if more speculatively, it seems possible there may be other cultural factors at play which support change; for example, the high value placed on technological innovations in the organisation.

Another important issue concerns the values, attitudes and behaviour of users of the service. These seem to have little influence on the organisational culture of ambulance services (unlike the fans in Ogbonna and Harris' football club study). This is significant; not least because of differences in perception about the appropriateness of emergency calls. The notable increase in demand for ambulance services and emergency services in general, needs to be explored, as this is a major area of friction between ambulance professionals, managers and users. The potential political saliency of this issue is revealed through the high profile of ambulance services and their perceived failings, plus the criticism of the public and their alleged 'misuse' of 999 calls across the spectrum of emergency services. This too is clearly in need of research and policy attention.

This discussion can be linked to the concept of rationality clusters. Broadbent and Laughlin (2009) draw on the work of Otley and Ferreira; especially Ferreira and Otley (2009), which develops a performance management systems framework based on factors identified in the contingency theory literature (see Figure 1).

Figure 1 here 
Broadbent and Laughlin classify these factors into: means, ends and context and introduce the notions of instrumental and communicative rationality (see Figure 2); thus identifying two potential rationality clusters.

\section{Figure 2 here}

In an instrumental rationality cluster, performance measures are generated by formal rationality (the provision of need expressed in numerical, calculable terms); i.e. the measures come first and assume implied values (e.g. profit maximisation). Instrumental rationality is also associated with theoretical rationality (a purely conceptual mastery of the world). Under instrumental rationality, 'ownership' of performance measures by stakeholders may be difficult to achieve, leading to displacement of established norms of behaviour, alienation and resistance. Operationalising such imposition may rely on legalrational authority, in Weber's term.

By contrast, in a communicative rationality cluster, the performance measures are determined by substantive rationality (i.e. discussed and agreed discursively, in line with agreed goals) and the use of practical rationality (which combines mental understanding and physical capability). The resulting Performance Management System (PMS) is more likely to be 'owned' by stakeholders. Here Broadbent and Laughlin draw on the work of Habermas. Hence, operationalisation requires reflexive authority, i.e. the acceptance legitimate authority structures can be built on participation, discussion, reflection, negotiation and reconciliation.

Transactional PMSs are then associated with instrumental rationality. They relate to highly specified ends, defined as specific targets and performance indicators, and often to highly specified means as well. Similarly, Relational PMSs are associated with communicative rationality. Both ends and means are chosen deliberatively by participants and there may be less specific performance measures selected. Note, however, that these are ideal types and Broadbent ands Laughlin acknowledge that empirical work is needed to place actual organisations on a continuum between the poles.

This can be related to the ambulance service as follows. Historically it has been a uniformed emergency service with a strong rational-legal authority structure and a culture which valued speedy responses, dealing 'heroically' with extreme situations and using a narrow but critically important range of skills around stabilisation. Significant artefacts include uniforms, flashing lights and time targets. This seems relatively well suited to the instrumental rationality cluster. However, the service has been moving to greater integration with the wider NHS and the utilisation of a wider range of skills, frequently applied in more routine situations, with the adoption of a broader set of performance indicators. Artefacts might include advanced diplomas and degrees. This seems like an evolution towards a situation more suited to the communicative rationality cluster. However, and paradoxically, the attempt to achieve this transition has been notably 
lacking in participation and deliberation, leading to resistance, which derives support from the existing culture(s).

These developments in ideas around the nature of PMSs can be reflected in the development of the concept of New Public Governance (NPG), which Osborne sees as superseding the concept of New Public Management (NPM). Osborne (2006, 2010) has argued that NPG has arisen from the demands arising out of an increasingly pluralistic state, in which the range of actors involved in the delivery of public services has expanded. There is therefore a need to take on board the views of a wider set of service providers, including allied and newly established professions, as well as service users. The range of perspectives identified in our study reveals the nature of a developing set of sub-cultures within an increasingly professionalised service. The challenge presented by the work of Ogbonna and Harris $(2014,2015)$ is for future studies to explore the perspectives of service users, and that an NPG approach should embrace the concept of Relational PMs in the development of more sophisticated and sustainable methods for assessing the effective delivery of those services.

There are some limitations to the study. The evidence gathered comes from a single large NHS ambulance trust in England, which raises questions about the applicability of these findings in other settings. Data was collected during 2007-2009 and further empirical research would be valuable to test the continuing relevance of the findings. However, the evidence gathered in the study corresponds to the issues raised in recent studies examining cultural characteristics and their implications for ambulance services (Fisher et al. 2015; Wankhade et al. 2015). Globally, ambulance services are facing similar challenges surrounding rising activity, an ageing population, societal issues and a drive for professionalization of practice and face similar cultural obstacles in evolving into professional healthcare providers (Hou et al. 2013). Findings from this study, therefore, have international implications and further comparative research can investigate these issues pertinently in different settings (see Jormakka and Saikko, 2015; Middleton 2015; Vincent-Lambert 2015).

\section{CONCLUSION}

Organisational culture is a complex and amorphous concept, subject to various local contingencies, and is difficult to change. The changing role and identity of ambulance personnel and the conflict between professional cultures and management objectives are significant issues in ambulance services. Indeed aspects of culture can act to impede government policy. Moreover, the contrasts between the complexity of culture and the simpler nature of performance measurement have significant implications for policy and practice. All these issues make this a fascinating topic for further study and research.

The framework of Obgonna and Harris (2014) has helped to categorise those aspects, which reinforced cultural perpetuation at Delta and reduced the effectiveness of efforts to reform the service. This demonstrates the applicability of their conceptual framework in a setting rather different from where it was applied originally. The five factors all seem to 
be significant with regard to cultural change and perpetuation in this case; although in some ways more ambiguously than in the football club case.

To conclude, therefore, the role of cultural perpetuation and sub-cultural dynamics and the influence of external stakeholders are both key issues within the complex nature of the ambulance service and the NHS more generally. Our discussion has centred largely on the findings of research into the internal relationships and dynamics within Delta. Further research is also needed into the efficacy of recent developments in education at the level of Higher Education in furthering professionalization and how that plays off against socialisation into 'tribal' sub-cultures. A key question for further possibly productive research is whether such developments have a significant and indeed longterm impact on the culture of the service. Likewise inquiry into whether culture(s) in ambulance services could and/or should be more receptive to the views of service users would be valuable. Finally, the effects of the current performance management regime on culture also deserve investigation.

\section{References}

Association of Ambulance Chief Executives AACE 2011. Taking Healthcare to the Patient 2: A review of 6 years' progress and recommendations for the future. London: Association of Ambulance Chief Executives.

Anand, V., Ashforth, B.E., and Joshi, M. 2005. "The Acceptance and Perpetuation of Corruption in Organizations". The Academy of Management Executive 19(4): 9-23.

Blaber, A., and Harris, H. 2014. Clinical Leadership for Paramedics. Berkshire: Open University Press.

Browaeys, M-J., and Price, R. 2008. Understanding Cross-Cultural Management Harlow: Pearson.

Broadbent, J., and Laughlin, R. 2009. "Performance management systems: A conceptual model”. Management Accounting Research 20(4): 283-295.

Charmaz, K. 2003. "Qualitative interviewing and grounded theory analysis", In Inside Interviewing: New Lenses, New Concerns, edited by Holstein, J.A., and Gubrium, J.F. London: Sage.

Care Quality Commission. 2015. London Ambulance Service NHS Trust: Quality Report London: CQC.

College of Paramedics. 2015. Paramedic Curriculum Guidance. Bridgewater: The College of Paramedics. 
Currie, G., and Procter, S. 2005. "The Antecedents of Middle Managers' Strategic Contribution: The Case of a Professional Bureaucracy". Journal of Management Studies 42(7): 1325-1356.

Department of Health. 2005. Taking Healthcare to the Patient; Transforming NHS Ambulance Services. London: Department of Health.

Eisenhardt, K. M., and Graebner, M.E. 2007. "Theory building from cases: opportunities and challenges". Academy of Management Journal 50: 25-32.

Ferreira, A., and Otley, D. 2009. "The design and use of performance management systems: An extended framework for analysis". Management Accounting Research 20(4): 263-282.

First, S., Tomlins, T., and Swinburn, A. 2012. "From Trade to Profession - the professionalization of the paramedic workforce". Journal of Paramedic Practice 4 (7): 378-381.

Fitzgerald, A., and Teal, G. 2004. "Health reform, professional identity and occupational sub-cultures: The changing interprofessional relations between doctors and nurses". Contemporary Nurse 16 (1-2): 71-79.

Fisher J.D., Freeman, K., Clarke, A., Spurgeon, P., Smyth, M., Perkins, G., Sujan, M., and Cooke, M. 2015. "Patient safety in ambulance services: a scoping review". Health Service and Delivery Research 3(21):1-278.

Francis, R. 2013. Mid Staffordshire NHS Foundation Trust Public Inquiry. Final Report London: The Stationery Office.

Harris, L.C., and Ogbonna, E. 1998. "Employee reactions to organizational culture change efforts". Human Resource Management Journal 8(2): 78-92.

Hatch, M.J. 1993. "The Dynamics of Organizational Culture". Academy of Management Review 18(4): 657-693.

Heath, G., and Radcliffe, J. 2007. "Performance measurement and the English ambulance service". Public Money \& Management 27(3): 223-227.

Heath, G., and Radcliffe, J. 2010. "Exploring the utility of current performance measures for changing roles and practices of ambulance paramedics". Public Money \& Management 30 (3): 151-158.

Heath, G., and Wankhade, P. 2014. "A Balanced Judgement?: Performance Indicators, Quality and the English Ambulance Service; some issues, developments and a research agenda". The Journal of Finance and Management in Public Services 13(1):1-19. 
Hou, X., Rego, J., and Service, M. 2013. "Paramedic education opportunities and challenges in Australia". Emergency Medicine Australasia 25(2): 114-119.

Jormakka, J. and Saikko, S. 2015. International Perspectives: Finnish Ambulance Services in 2010, in Wankhade, P. and Mackway-Jones, K. (eds) Ambulance Services: Leadership and Management Perspectives, New York: Springer.

Jorritsma, P.Y., and Wilderom, C. 2012. "Failed culture change aimed at more service provision: a test of three agentic factors". Journal of Organizational Change Management 25(3): $364-391$.

Kirkup, B. 2015. The Report of the Morecambe Bay Investigation. London: The Stationery Office.

Konteh, F.H., Mannion, R., and Davis, H.T.O. 2010. "Understanding Culture and Culture Management in the English NHS: a comparison of professional and patient perspectives". Journal of Evaluation in Clinical Practice 17: 111-117.

Kotter, J.P., and Heskett, J.L. 2011. Corporate Culture and Performance. New York: Free Press.

Lincoln, Y.S., and Guba, E.G. 1985. Naturalist Inquiry. New York: Sage.

Lovegrove, M., and Davis, J. 2013. Paramedic Evidence Based Education Project (PEEP): End of Study Report. London: Allied Health Solutions.

Mannion, R., Davies, H., and Marshall, M. 2005. Cultures for Performance in Health Care. Maidenhead: Open University Press.

Martin, J. 1985. "Can organizational culture be managed?", In Organizational Culture: the Meaning of Life in the Workplace, edited by Frost, P., Moore, L., Louis, M., Lundburg, C. and Martin, J. Thousand Oaks, CA: Sage.

McCann, J., Granter, E., Hyde, P., and Hassard, J. 2013. "Still Blue-Collar after all these Years? An Ethnography of the Professionalization of Emergency Ambulance Work". Journal of Management Studies 50 (5): 750-776.

Middleton, P. 2015. "International Perspectives: Australian Ambulance Services 2010”, in Ambulance Services: Leadership and Management Perspectives, edited by Wankhade, P., and Mackway-Jones, K. New York: Springer.

Morgan, P. I., and Ogbonna, E. 2008. "Subcultural dynamics in transformation: a multiperspective study of healthcare professionals". Human Relations 61: 39-65. 
National Audit Office. 2011. Transforming NHS ambulance services. London: The Stationery Office.

NHS England. 2013. Transforming Urgent and Emergency Care in England: Urgent and Emergency Care Review, Phase 1 Report. London: NHS England.

Ogbonna, E., and Harris, L.C. 2002. "Managing organizational culture: insights from the hospitality industry". Human Resource Management Journal 12: 33-53.

Ogbonna, E., and Harris, L.C. 2014. "Organizational Cultural Perpetuation: A Case Study of an English Premier League Football Club". British Journal of Management 25: 667686.

Ogbonna, E., and Harris, L.C. 2015. "Subcultural tensions in managing organizational culture: a study of an English Premier League football organisation." Human Resource Management Journal 25(2): 217-232.

O'Hara, R., Johnson, M., Siriwardena, A.N., Weyman, A., Turner, J., Shaw, D., Mortimer, P., Newman, C., Hirst, E., Storey, M., Mason, S., Quinn, I. and Shewan, J. 2015. “A qualitative study of systemic influences on paramedic decision making: care transitions and patient safety". Journal of Health Services Research \& Policy 20: 45-53.

Osborne, S.P. 2006. “The New Public Governance?” Public Administration Review 8 (30): $377-388$

Osborne, S.P. ed. 2010. The New Public Governance? Emerging perspectives on the theory and practice of public governance. London: Routledge.

Pollock, A.C. 2013. "Ambulance services in London and Great Britain from 1860 until today: a glimpse of history gleaned mainly from the pages of contemporary journals". Emergency Medical Journal 30 (3): 218-22.

Radcliffe, J., and Heath, G. 2009. "Ambulance calls and cancellations: policy and implementation issues". International Journal of Public Sector Management 22 (5): $410-22$.

Scase, R., and Goffee, R. 1989. Reluctant Managers: Their Work and Life Styles. New York: Allen \& Unwin.

Schein, E.H. 2011. "The psychological life of organizations" In Handbook of Organizational Culture and Climate, edited by Ashkanasy, N.M., Wilderom, C.P.M. and Peterson, M.F. Thousand Oaks, CA: Sage.

Schein, E.H. 1996. "Three Cultures of Management: The Key to Organizational Learning”. Sloan Management Review 38 (1): 9-20. 
Schein, E.H. 1985. Organisational Culture and Leadership. San Francisco: Josse-Bass.

Schneider, B., Ehrhart, M.G., and Macey, W.H. 2011. "Organizational climate research: achievements and the road ahead" In Handbook of Organizational Culture and Climate, edited by Ashkanasy, N.M., Wilderom, C.P.M. and Peterson, Thousand Oaks, CA: Sage.

Smircich, L. 1983. "Concepts of culture and organizational analysis". Administrative Science Quarterly 28: 339-358.

Vincent-Lambert, C. 2015. "International Perspectives: South African Ambulance Services in 2020" In Ambulance Services: Leadership and Management Perspectives, edited by Wankhade, P., and Mackway-Jones, K. New York: Springer.

Wankhade, P. 2011. "Performance measurement and the UK emergency ambulance service: Unintended Consequences of the ambulance response time targets". International Journal of Public Sector Management 24 (5): 384-402.

Wankhade, P. 2012. "Different cultures of management and their relationships with organizational performance: evidence from the UK ambulance service". Public Money \& Management 32 (5): 381-388.

Wankhade, P., and Brinkman, J. 2014. "The negative consequences of culture change management: evidence from a UK NHS ambulance service". International Journal of Public Sector Management 27 (1): 2-25.

Wankhade, P., and Mackway-Jones, K. 2015. "Introduction: Understanding the Management of Ambulance Services", In Ambulance Services: Leadership and

Management Perspectives, edited by Wankhade, P., and Mackway-Jones, K. New York: Springer.

Wankhade, P., Radcliffe, J., and Heath, G. 2015. "Organisational and Professional Cultures: An Ambulance Perspective", In Ambulance Services: Leadership and Management Perspectives, edited by Wankhade, P., and Mackway-Jones, K. New York: Springer.

Wilderom, C., Glunk, U., and Maslowski, R. 2000. "Organizational culture as a predictor or organizational performance", In Handbook of Organizational Culture and Climate edited by Ashkanasy, N., Wilderom, C., and Peterson, M. Thousand Oaks, CA: Sage.

Williams van Rooij, S. 2011. "Higher education sub-cultures and open source adoption". Computers \& Education 57 (1): 1171-1183. 